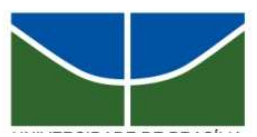

UNIVERSIDADE DE BRASÍLIA

Centro de Excelência em Turismo

Pós-graduação Lato Sensu

Curso de Especialização em Qualidade em Alimentos

\title{
MASSAS PARA PIZZA COM RESTRIÇÃO DE GLÚTEN
}

Adenilma da Silva Farias

Pofa. Dra. Raquel Braz Assunção Botelho

Brasília

2009 


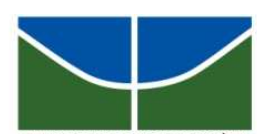

UNIVERSIDADE DE BRASÍLIA

Centro de Excelência em Turismo

Pós-graduação Lato Sensu

Curso de Especialização em Qualidade em Alimentos

\title{
MASSAS PARA PIZZA COM RESTRIÇÃO DE GLÚTEN
}

\author{
Adenilma da Silva Farias \\ Pofa. Dra. Raquel Braz Assunção Botelho \\ Monografia apresentada ao Centro de Excelência em \\ Turismo - CET, da Universidade de Brasília - UnB, \\ como requisito parcial à obtenção do grau de \\ Especialista em Qualidade em Alimentos.
}

Brasília

2009 
Farias, Adenilma da Silva.

Massas para Pizza com Restrição de Glúten / Adenilma da Silva Farias. - Brasília, 2009.

$41 \mathrm{f}$.

Monografia de Especialização apresentada ao Curso de Especialização em Qualidade em Alimentos - Universidade de Brasília, Centro de Excelência em Turismo, 2009.

Orientador: Dra. Raquel Braz Assunção Botelho.

1. Glúten. 2. Doença Celíaca. 3. Arroz. 4. Pizza. 
UNIVERSIDADE DE BRASÍLIA

Centro de Excelência em Turismo

Pós-graduação Lato Sensu

Curso de Especialização em Qualidade em Alimentos

Adenilma da Silva Farias

Aprovado por:

Professor orientador: Dra. Raquel Braz Assunção Botelho

Professor: Dra. Rita de Cássia Coelho de Almeida Akutsu

Professor: Dra. Wilma Maria Coelho Araújo

Brasília, 13 de abril de 2009. 


\section{DEDICATÓRIA}

Aos meus Pais, por muito acreditarem em meu esforço.

Aos meus queridos amigos, por se fazerem presente mesmo distantes.

À mestre amiga, Pós-Dra Regilda Moreira-Araújo, por contribuir com minha formação profissional e pessoal. 


\section{AGRADECIMENTOS}

À Profa. Dra Raquel Botelho pela confiança, orientação, apoio e por se mostrar sempre disposta a ajudar com suas sábias sugestões.

Ao Sr. Francisco, técnico do Laboratório de Técnica Dietética, por muito ajudar na execução de meu trabalho.

Ao Sr. Paulo Roberto, Presidente da Associação de Celíacos de Brasília, pela preciosa colaboração.

Aos membros da Associação de Celíacos de Brasília, pela imensa colaboração na realização desta pesquisa.

À futura Nutricionista Luciana Lemos, aluna do Curso de Nutrição da UnB, pela colaboração e destreza durante a realização deste trabalho.

Ao Sr. Marcos Araújo, por estar sempre disposto a me ajudar em minhas análises de dados.

A todos que colaboraram na realização desta pesquisa e que, por descuido, eu não tenha mencionado, minha eterna gratidão. 


\section{EPÍGRAFE}

"A alimentação é um dos principais fatores da felicidade social. Os povos bem alimentados são os de maior capacidade. E só a estes, a prosperidade abre os seus braços agasalhadores e amigos." (COSTA, 1938) 


\section{SUMÁRIO}

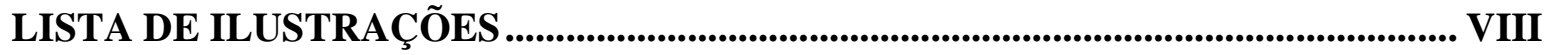

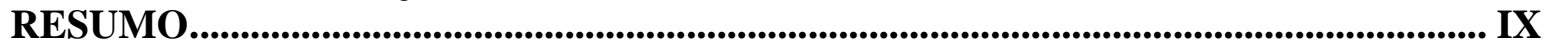

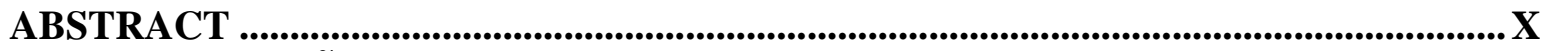

1 INTRODUÇÃ

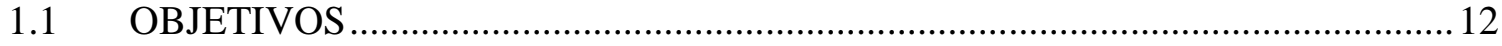

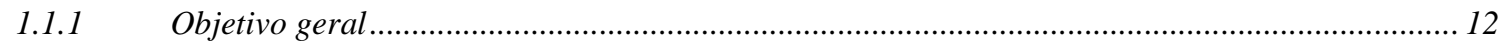

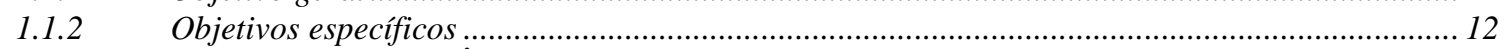

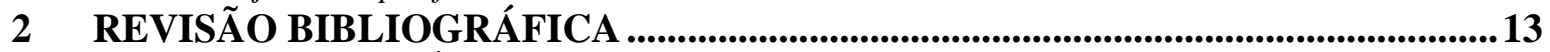

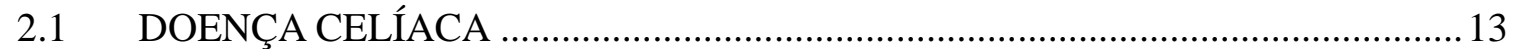

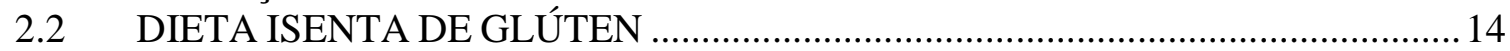

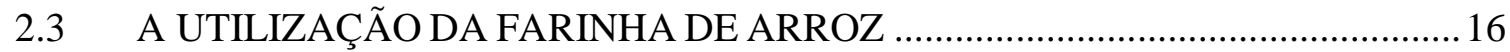

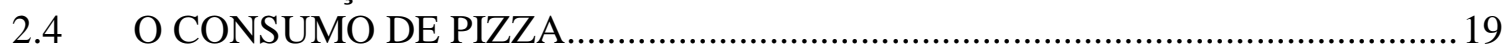

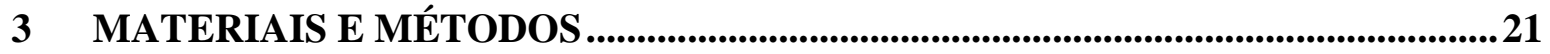

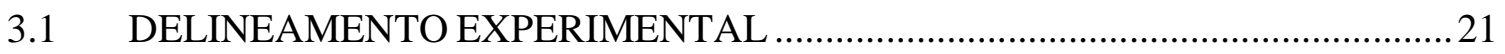

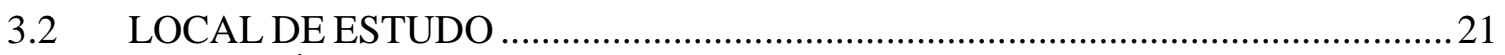

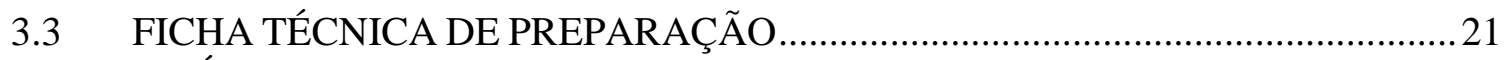

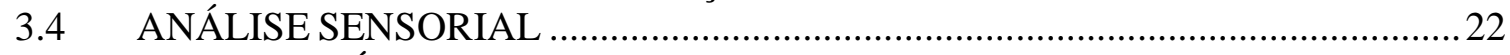

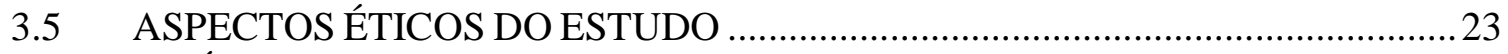

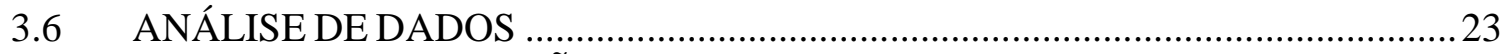

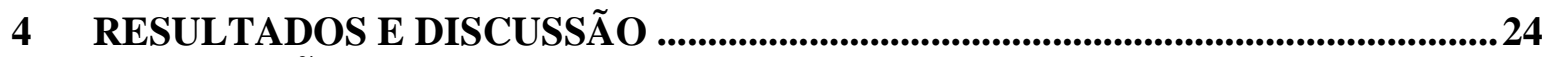

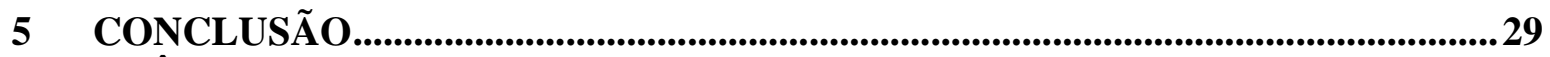

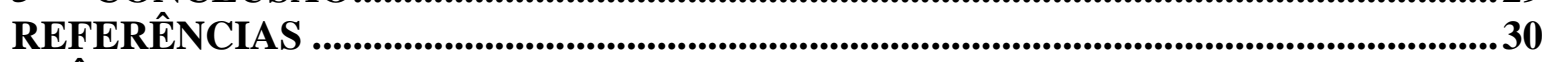

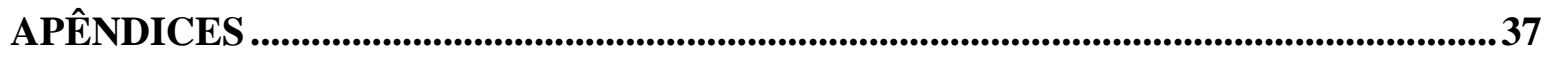




\section{LISTA DE ILUSTRAÇÕES}

Figura 01-Modelo de ficha de análise sensorial.:

Tabela 01 - Percentual de ingredientes das preparações de massa para pizza a partir de farinha de arroz refinada, farinha de arroz flocada, arroz polido e farinha de trigo. Brasília-DF, 2008 .

Tabela 02 - Amostras de massas para pizza e custo obtido em 100g das preparações. BrasíliaDF, 2008:

Tabela 03 - Comparação de macronutrientes e micronutrientes das massas elaboradas a partir de farinha de arroz flocada, farinha de arroz refinada, arroz polido e farinha de trigo sem recheio. Brasília-DF, 2008.. 26

Tabela 04 - Médias de aceitação das variáveis analisadas nas três amostras modificadas de pizza. Brasília-DF, 2008.: 


\section{RESUMO}

A Doença Celíaca é uma enteropatia que atinge indivíduos geneticamente susceptíveis. Ela pode apresentar-se na forma sintomática ou assintomática, tendo como principal sinal a alteração das vilosidades da mucosa jejunal. Seu tratamento é basicamente dietético, onde a exclusão total do glúten reflete no desaparecimento dos sintomas manifestados. O objetivo deste trabalho foi elaborar massas de pizza para portadores de Doença Celíaca a base de arroz e derivados. Durante o estudo foram elaborados três tipos de massa para pizza, uma de arroz polido, uma de farinha de arroz refinada e outra de farinha de arroz flocada. Foram elaboradas a Fichas Técnicas de Preparação e realizada análise sensorial das três formulações. Com as Fichas Técnicas de Preparação pôde-se obter as informações nutricionais dos produtos. A análise sensorial foi realizada com 42 provadores, utilizando-se a escala hedônica não estruturada de 9 $\mathrm{cm}$. As análises estatísticas foram feitas com ANOVA e Teste de Tukey. As informações nutricionais revelaram que a massa elaborada com arroz polido apresentou menor VET, menor quantidade de carboidrato e lipídeo e maior quantidade de proteína comparada às massas de farinha flocada e refinada. Comparando-se com a receita tradicional, as massas formuladas apresentaram menor VET, menores quantidades de proteína e lipídeo. O resultado das análises sensoriais mostrou que não há diferença significativa entre as amostras, sendo que todas foram aceitas e apresentaram características semelhantes com relação à aparência, ao sabor, ao aroma e a impressão global. Com isto pode-se concluir que o arroz e seus subprodutos são matériasprimas aceitáveis na elaboração de massa para pizza e que podem ser introduzidas na dieta dos portadores de doença celíaca.

Palavras-chave: Glúten, Doença Celíaca, Arroz, Pizza. 


\begin{abstract}
The Celiac Disease is a entheropathy that reaches susceptive genetically individuals. It can present itself in the symptomatic or non symptomatic form, having as main signal the alteration of the jejunal membrane. Its treatment is basically dietary, where the total exclusion of gluten reflects in the disappearance of the revealed symptoms. The objective of this study was to elaborate products for Celiac Disease patients based on rice and its products. During the study three types of doughs for pizza were elaborated, one with polishing rice, one with refined rice flour and another one with flaked rice flour. Technical preparation files were constructed and sensorial analysis of the three formularizations were carried out. With the technical preparation file it was possible to obtain the nutritional information of the products. The dough prepared with polished rice presented less caloric value as well as carbohydrate and fat content. Comparing the doughs with the original one, the formulated doughs presented less Energetic Total Value, and amounts of protein and lipid. The sensorial analysis was carried through with 42 individuals, using a not structuralized hedonic scales of $9 \mathrm{~cm}$. The statistical analyses were performed with ANOVA and Tukey Test. The result of the analyses showed that it does not have significant difference between the samples. All were accepted and presented good characteristic with regard to appearance, flavor, aroma and global impression. It can be concluded that the rice and its byproducts are acceptable raw materials in the elaboration of pizza doughs and that they can be introduced in the diet of celiac disease individuals.
\end{abstract}

Keywords: Gluten, Celiac Disease, Rice, Pizza. 


\section{Introdução}

A doença celíaca (DC) é uma enteropatia causada pelo efeito tóxico das prolaminas, proteínas que fazem parte do glúten (KOTZE, 2001), em indivíduos com predisposição genética, ocorrendo atrofia total ou subtotal das vilosidades da mucosa do intestino delgado, que resulta na má absorção de nutrientes na dieta, principalmente de lipídeos, carboidratos, proteínas, ferro, magnésio, zinco e vitaminas lipossolúveis (MORAIS et al., 2001).

Antigamente, a DC era considerada uma patologia rara específica de crianças caucasianas, hoje é vista como uma condição que atinge boa parte da população mundial, chegando a afetar cerca 1:100 a 1:300 pessoas. Estudos revelam que a relação de mulheres e homens portadores de DC é de 2:1. Sabe-se também que há mais casos não diagnosticados do que casos diagnosticados da doença, fato conhecido como "iceberg celíaco", onde a parcela não diagnosticada representa a parte submersa do iceberg (WGO, 2005).

Os poucos estudos realizados no Brasil mostram que a DC não é uma doença rara no país. Gandolfi et al. (2000) estudaram doadores de sangue saudáveis em Brasília e constataram a prevalência de 1:681 de DC não diagnosticada. Alencar (2007) realizou um estudo semelhante na cidade de São Paulo e encontrou a prevalência de 1:286 de DC não diagnosticada em doadores de sangue. Pereira et al. (2006) constataram a prevalência de DC de 1:417 em doadores de sangue de Curitiba.

Sabe-se que os alimentos isentos de glúten são muito importantes para pessoas portadoras de doença celíaca. No entanto, existem poucos alimentos alternativos para os produtos de maior consumo, como: pães, massas, bolachas, doces e farináceos; além disso, há casos de incorreta inscrição dos ingredientes nos rótulos dos alimentos e de contaminação com glúten de determinado produto industrializado (ACELBRA, 2006).

A farinha de trigo é a principal fonte de glúten na alimentação humana, por ser o principal ingrediente das massas convencionais, no entanto, muitos estudos já comprovaram que é possível a substituição parcial ou total da farinha de trigo na preparação de massas por outras de maior valor nutritivo ou com conteúdo maior de fibras e carboidratos complexos, podendo-se utilizar na substituição farinha de milho, farinha de arroz e farinha de mandioca. (SIMBALISTA; ARÊAS, 2006). Ormenese (2002) cita o arroz como o substituto menos alergênico dentre os cereais, quando comparando a soja, ao milho, a batata, a mandioca e ao cará. 
O arroz é o principal produto da cesta básica do brasileiro, que destina cerca de $22 \%$ do seu orçamento em alimentação (EMBRAPA, 2005). A forma de consumo do arroz no Brasil difere-se de grãos como o trigo e o milho por não ser transformado em outros produtos antes do consumo, ou seja, é consumido principalmente na forma de grãos inteiros, descascados e polidos (CASTRO et al., 1999).

Apesar do crescimento na produção de alimentos isentos de glúten, a oferta dos produtos de preço acessível está mais centrada na fabricação artesanal. Os portadores de DC ainda se deparam com alimentos industrializados desta espécie de valor aquisitivo bastante elevado, que são encontrados principalmente em lojas destinadas a alimentos para fins especiais. A dificuldade de tratamento dos portadores com pouca renda é um dos estímulos aos pesquisadores da área de alimentação. Por ser um produto de baixo custo e de pouca utilização, a farinha de arroz torna-se uma alternativa economicamente e nutricionalmente atrativa. Faz-se então relevante a elaboração de novos produtos a partir desta matéria-prima, objetivando-se melhorar a qualidade nutricional e longevidade dos que deles necessitam.

\section{1- Objetivos:}

\subsection{1- Objetivo Geral:}

Desenvolver massas alimentícias para produção de pizza para portadores de Doença Celíaca a base de arroz e derivados.

\subsection{2- Objetivos Específicos:}

- $\quad$ Formular três diferentes massas para pizza a base de farinha de arroz refinada, farinha de arroz flocada e arroz polido;

- $\quad$ Realizar análise sensorial;

- Determinar a aceitabilidade dos produtos;

- Avaliar as características nutricionais dos produtos;

- Determinar o custo das preparações. 


\section{Revisão Bibliográfica}

\section{1- Doença Celíaca}

Doença celíaca é uma enfermidade digestiva caracterizada pela intolerância permanente ao glúten, cujo tratamento, basicamente dietético, consiste na exclusão total desta proteína da dieta (SDEPANIAN et al., 1999). O cumprimento rigoroso da dieta sem glúten, garante ao portador desta patologia o desenvolvimento pôndero-estatural e puberal adequados, densidade mineral óssea, fertilidade, redução de risco de deficiência de macro e micronutrientes, além de diminuir o risco do surgimento de doenças malignas, particularmente do sistema digestivo (SDEPANIAN et al., 2001a). Pratesi e Gandolfi (2005) consideram a DC como sendo um problema de saúde pública, devido à alta prevalência, grande associação com morbidade variável e não-específica e à probabilidade aumentada de aparecimento de complicações graves, principalmente osteoporose e doenças malignas do trato gastroentérico.

A doença manifesta-se com ou sem sintomas. No primeiro caso, há duas formas: clássica e não clássica, além da assintomática (ACELBRA, 2006).

A forma típica ou clássica da DC inicia-se nos primeiros anos de vida, os sintomas mais comuns são diarréia crônica, perda de peso, distensão abdominal, apatia, anorexia e palidez. A forma atípica ou não-clássica apresenta-se mais tardiamente na infância e pode apresentar-se com vários sintomas, como baixa estatura, anemia ferropriva não curável, dor abdominal, constipação intestinal, osteoporose, infertilidade. Na forma assintomática, há alterações de anticorpos e de vilosidades da mucosa jejunal, sem manifestações clínicas. A total suspensão da dieta dos produtos alimentícios contendo glúten ocasiona na normalidade dos sintomas descritos nas três formas clínicas (SDEPNIAN et al., 1999).

A utilização de dieta isenta de glúten de forma permanente é a principal forma de tratamento da DC, devendo-se excluir os seguintes cereais e seus derivados: trigo, centeio, cevada e aveia. As frações protéicas do glúten tóxicas ao paciente com DC (prolaminas) diferemse de acordo com o tipo de cereal: gliadina no trigo, hordeína na cevada, secalina no centeio e avenina na aveia (THOMPSON, 1997). 
O tratamento sob dieta isenta de glúten deve ser adotado por toda a vida a partir do diagnóstico da DC, pois ele é o mais eficaz. A dieta sem glúten deve ser bem planejada, levando em consideração fatores importantes como: situação fisiopatológica e necessidades nutricionais que se relacionam com a idade do paciente, etapa evolutiva da DC e gravidade do doente. Uma dieta de restrição deve levar em conta as necessidades individualizadas do paciente, pois escolhas ou forma de preparo inadequada pode levar ao retrocesso do quadro clínico. Sendo assim, as quatro leis da alimentação devem ser seguidas, pois as necessidades nutricionais do individuo devem ser respeitadas e em conjunto devem-se procurar alternativas para a total substituição do glúten por outras proteínas de fontes vegetais e animais (KOTZE, 2006).

Para portador de DC é importante assegurar que um o produto é isento de glúten, devendo-se ter o cuidado de ler os rótulos dos alimentos ou contatando o fabricante. Comer e cozer alimentos isentos de glúten tornou-se mais fácil nos últimos anos, em virtude do aumento no número e na qualidade dos produtos livres de glúten que estão disponíveis em algumas lojas de alimentos, no entanto com preços elevados. A disponibilidade de alimentos livres de glúten aumenta a possibilidade de escolhas de um paciente e melhora a variedade da dieta ao permitir que os mesmos sintam-se "normais" ao comer entre seus familiares (NIEWINSKI, 2008; LEE et al., 2007).

\section{2- Dieta Isenta de Glúten}

O crescimento e a textura das massas são diretamente influenciados pela presença do glúten, sendo que as farinhas com maior quantidade de glúten são melhores para preparar pães e massas para macarrão. Já em preparações como bolo, bolacha, massa de torta, de pizza, a ausência do glúten não afeta as características do produto final, pois quanto menos glúten tiver a farinha, mais mole será a massa e mais adequada para estas preparações (ESASHIRA et al., 1986; ORNELLAS, 2001).

Em pesquisa realizada por ESASHIRA et al. (1986), onde se procurou conhecer as preferências alimentares de alguns portadores de DC, independente da sua restrição alimentar, os alimentos referidos por ordem decrescente foram: pão, chocolate, massas em geral (macarrão, pizza, nhoque) e embutidos (salsicha, lingüiça, mortadela). 
As preparações caseiras de alimentos alternativos são o reflexo da pouca disponibilidade de alimentos já prontos no mercado brasileiro, o que não é de difícil aceitação, pois a culinária local já possui receitas com as farinhas de cereais permitidos no preparo de bolos, bolachas, sobremesas etc. (KOTZE, 2006).

Apesar de parecer simples, o tratamento da DC apresenta inúmeras dificuldades, dentre elas a pouca disponibilidade de tempo para o preparo de alimentos modificados, o que interfere na continuidade da dieta, afetando principalmente as crianças, que dependem de seus responsáveis para preparação de suas refeições e geralmente optam por ofertar alimentos que não exigem muita manipulação como frutas, mingaus e ovos cozidos, tornando a dieta monótona, podendo levar a anorexia, prejudicando o estado nutricional de celíacos já debilitados nutricionalmente. Este quadro pode ainda ser pior para crianças em idades mais avançadas, como na fase escolar, pois a dieta pode ser transgredida devido a diversos fatores como vergonha de levar seu lanche de casa ou impossibilidade de levar o lanche e de consumir a merenda escolar oferecida, geralmente composta por macarrão, pão, bolacha (ESASHIRA et al., 1986).

A dificuldade de introduzir alguns alimentos industrializados no plano dietoterápico dos celíacos está no fato destes alimentos não apresentarem o trigo somente como ingrediente, mas na possibilidade de apresentá-lo como espessante ou como veículo para temperos ou mistura para homogeneização de certos produtos, impossibilitando a utilização destes alimentos na orientação dietética (ESASHIRA et al., 1986). Além disso, alguns medicamentos possuem gliadina, fração protéica do glúten no trigo, em sua composição, limitando a restrição ao consumo de glúten, caso algum paciente necessite utilizar um destes medicamentos (SDEPANIAN et al., 2001b).

A composição da dieta isenta de glúten varia em cada país. Nos Estados Unidos, uma dieta sem glúten é composta basicamente por arroz e milho, que são naturalmente isentos de glúten. Na Escandinávia e no Reino Unido, uma dieta sem glúten pode incluir o amido de trigo, que foi transformado em alimento isento de glúten (THOMPSON, 2001).

Vários estudos já foram feitos com o objetivo de substituir as farinhas fontes de glúten. Produtos como sarraceno, fécula de batata, milho, polvilho, farinha de arroz, quinoa e amaranto foram objetos de estudo em preparações para celíacos (ESASHIRA et al., 1986).

Ormenese et al.(2001) testaram a aceitação de macarrão de arroz com 40 provadores portadores de DC, onde os degustadores receberam as amostras em suas residências com as 
devidas instruções de consumo. Entre os indivíduos recrutados, 29 avaliaram a amostra e devolveram o formulário de avaliação. No estudo, foram avaliados atributos como aparência antes do preparo, textura e sabor, que foram considerados entre bom e excelente por $86 \%, 76 \%$ e $78,5 \%$ dos provadores respectivamente.

López et al. (2004) elaboraram pães de forma a partir dos amidos de milho, de mandioca e da farinha de arroz. No estudo, o pão de farinha de arroz foi o preferido pelos provadores, apresentando os melhores parâmetros, o segundo na preferência foi o de amido de milho e por último de fécula de mandioca.

Zandonadi (2006) estudou a substituição do glúten pelo psyllium. Durante o trabalho elaborou um pão, um bolo, um biscoito, um macarrão e uma pizza, todos com farinhas alternativas, dentre elas o creme de arroz, acrescidas do psyllium, a fim de obter resultados semelhantes ao glúten com relação à textura dessas massas. As preparações foram submetidas à análise sensorial com 35 indivíduos celíacos e 35 não celíacos, que revelou a boa aceitação das mesmas pelos dois grupos.

\section{3- A Utilização da Farinha de Arroz}

Ormenese (2002) considera a produção de massas alimentícias de arroz muito importante para os celíacos, por ser um produto não disponível no mercado nacional, elaborado com cereal bastante difundido e aceito na culinária brasileira, além de uma boa alternativa para uso do arroz que se quebra durante o beneficiamento, considerado subproduto de baixo valor comercial e com pouca utilização industrial.

A inserção do arroz na economia mundial deve-se ao seu alto consumo pelas populações em todos os países, de todos os continentes, e em especial no continente asiático, que também apresenta a maior produção mundial. A China e a Índia produzem juntas 299,5 milhões de toneladas do produto por ano, representando $76,25 \%$ da produção mundial (BRUM; PORTELA, 2007).

Neves (2007) cita o Brasil como um dos nove maiores produtores de arroz, com o cultivo presente por todo território nacional, sendo que a produção está concentrada nas regiões Centro-Oeste, Sudeste e Sul, responsáveis por $74 \%$ de todo arroz produzido no País. O Maranhão 
é o maior produtor da região Nordeste, participando com $10 \%$ da produção nacional, seguido do Ceará, com apenas $1,8 \%$ da área cultivada e $1,7 \%$ da produção.

A grande concentração de cultivo orizícola no Brasil está no Rio Grande do Sul, que se tornou um dos principais fornecedores de arroz para as demais regiões do país (NEVES, 2007), fato que talvez seja justificado pela história, pois o cultivo deste cereal foi introduzido no país durante o século XVI e se desenvolveu efetivamente no Rio Grande do Sul a partir de 1930, estando a partir daí em contínuo avanço tecnológico, tornando-se economicamente importante para esta e demais regiões do país em toda sua cadeia produtiva. Tal evolução é vista positivamente não só pelo aspecto econômico do país e, em especial, para as regiões de produção orizícola sul-rio-grandense, mas pela sua relevância para a segurança alimentar de sua população (BRUM; PORTELA, 2007).

Mesmo com o alto consumo de arroz no Brasil, a década de 90 foi marcada pela diminuição do consumo deste cereal, além da diversificação do uso de proteínas animais, massas e produtos elaborados com maior valor agregado, causados pela expansão da massa salarial e melhoria do poder aquisitivo da população, reflexos da criação de um novo plano econômico no país, o Plano Real. Tomando-se por base o grão em casca, pode-se afirmar que o consumo médio de arroz no Brasil varia de 74 a $76 \mathrm{Kg} /$ habitante/ano (EMBRAPA, 2005).

Segundo o IBGE - Instituto Brasileiro de Geografia e Estatística (2009), a produção brasileira de arroz em 2008 foi de 12,1 milhões de toneladas, estimando-se um crescimento de $0,5 \%$ na safra em 2009.

Em se tratando de segurança alimentar mundial, o arroz tem papel fundamental, tanto economicamente quanto socialmente, chegando a ser considerado pela FAO (Food and Agriculture Organization) o alimento mais importante, visto que além de ter um ótimo balanceamento nutricional, sua versatilidade torna possível uma boa adaptação a diferentes tipos de solo e clima, podendo ser considerada a espécie de maior potencial de aumento de produção para o combate da fome no mundo (VIEIRA, 2007).

Tradicionalmente o arroz é consumido na forma de grãos inteiros, sofrendo pequena transformação na agroindústria, sendo que o estado físico do grão serve para classificá-lo quanto ao tipo, que vai do tipo 1 ao tipo 5. Apesar de existir uma variação de formas em que o arroz é consumido no Brasil e no mundo, os tipos de arroz mais consumidos no Brasil são o arroz polido, parbolizado e integral, apresentando uma migração do consumo do arroz tipo 2 para tipo 1, além 
do crescimento da demanda de arroz parbolizado, representando $20 \%$ deste consumo. A diversidade de formas variam em função da cultivar produzida ou do processo de beneficiamento (BARATA, 2005; EMBRAPA, 2005).

Durante o beneficiamento do arroz são separados do endosperma, parcial ou totalmente, o embrião e a película que recobre o grão, que resulta em grãos polidos (inteiros e quebrados), casca, farelo e impurezas. (CASTRO et al., 1999). O amido é o principal nutriente presente no arroz polido, que também contém proteína, fibras e vitaminas do complexo B, presentes nas camadas periféricas do grão. A maior presença de proteínas e lipídios está no germe ou embrião (NAVES, 2007).

Kennedy e Burlingame (2003) citam o arroz como um dos cereais básicos da dieta humana, pois ele fornece $20 \%$ da ingestão de energia e $15 \%$ do aporte de proteína no mundo. Nos países em desenvolvimento da Ásia o consumo de arroz chega a representar mais da metade do aporte energético e protéico dessas populações.

A partir do arroz, pode-se obter mais de 2000 produtos diferentes no mundo. Sob o ponto de vista econômico, essa versatilidade do arroz é benéfica, pois além de reduzir desperdícios, possibilita a fabricação de produtos com melhor valor nutricional, além do melhor aproveitamento de energia e de matéria-prima por parte da indústria, visto que na maioria delas, o arroz muito quebrado não tem total proveito (GUERREIRO, 2006).

Apesar de o arroz ser o fornecedor de $20 \%$ da fonte de energia alimentar do mundo, enquanto o trigo fornece $19 \%$ e o milho $5 \%$, existem poucos produtos derivados de arroz no mercado brasileiro, o que mostra a necessidade de mais estudos sobre farinha de arroz na fabricação de produtos alimentícios, favorecendo a população de uma forma geral e, em especial, os portadores de DC, que não podem ingerir glúten (GUERREIRO, 2006).

O aumento no uso de arroz na fabricação de produtos alimentares é resultado da crescente demanda por produtos mais saudáveis. Além disso, os produtos a base de arroz representam mais uma opção para consumidores com problemas alérgicos. A casca e o farelo são usados como fontes de energia e matérias-primas para produção de nutracêuticos e de concentrados de proteína (ROSEFL; MARCO, 2008).

$\mathrm{O}$ arroz quebrado, sem impurezas e com tratamento térmico necessário de inativação, dá origem à farinha de arroz, podendo a partir daí ser utilizada para fins alimentares, como substituto da farinha de trigo convencional ou outras farinhas fontes de glúten. Atualmente não há 
dados estatísticos oficiais publicados sobre a produção e o consumo de farinha de arroz (ORMENESE; CHANG, 2002).

Geralmente as farinhas de arroz têm a mesma composição química que os grãos quebrados e suas características são baseadas no tipo de cultivar, tipo de ambiente, método de moagem e forma de beneficiamento (ROSEFL; MARCO, 2008).

A farinha de arroz tem ganhado espaço na indústria alimentícia, sendo utilizada como ingrediente que pode aumentar o valor agregado do produto. As boas características organolépticas da farinha de arroz facilitam a introdução desta na fabricação de produtos convencionais, pois além de ter um sabor suave, é de fácil digestão, o que possibilita a utilização no preparo de alimentos como: sopas, mingaus, cereais matinais, molhos, cremes, macarrão, pão, produtos cárneos, sobremesas, entre outros (DORS et al., 2006; GALERA, 2006).

Apesar da farinha de arroz ser um ingrediente promissor na elaboração de produtos, não há no Brasil uma linha de produtos específica que se utilize desta matéria-prima, isso possibilita o desenvolvimento de produtos diferenciados, com um ingrediente economicamente viável, que possa trazer benefícios à saúde da população e com boas possibilidades de competir no mercado com produtos tradicionais em tempos de globalização, que induz a indústria a inserir novos produtos atrativos ao mercado consumidor. A boa qualidade nutricional, funcional e psicossensorial do arroz, além da grande participação no cardápio da população em geral fazem com que a farinha deste cereal seja um ingrediente apto a ser utilizado na elaboração de alimentos de conveniência ou para fins especiais, especificamente para pessoas alérgicas ao trigo ou com doença celíaca (DORS et al., 2006).

\section{4- O Consumo de Pizza}

Dentre os alimentos que os celíacos gostariam de encontrar com facilidade, a pizza aparece citada com um percentual de 11\%, segundo pesquisa realizada pela ACELBRA (2006).

A origem da pizza é italiana, sendo os ingredientes de sua massa básica os mesmos utilizados para a elaboração do pão: farinha de trigo, água, sal e leveduras (PHILIPPI, 2003).

A qualidade total de uma pizza depende principalmente da massa, cujas propriedades são afetadas pelo processo de fermentação, além do tipo de farinha e a forma de preparação (GALLAGHER, 2008). O formato da massa, espessura e sabor da pizza variam, podendo ser 
quadrada, redonda, espessa ou fina, coberta por uma camada de molho de tomate e acrescida dos ingredientes que irão compor seu recheio (PHILIPPI, 2003).

Como no pão, a farinha de trigo utilizada na massa de pizza deve ter uma matriz de glúten completamente desenvolvida com propriedade elástica e resistente para reter o dióxido de carbono durante o processo de fermentação. Poucos estudos estão disponíveis sobre desenvolvimento de massas para pizza sem glúten. Um estudo Irlandês relata que o amido de milho, que possui hidrocolóides, nas proporções corretas, pode produzir massas para pizza sem glúten de boa qualidade (GALLAGHER, 2008).

A pizza é um produto bastante consumido, devido sua praticidade, sabor agradável e valor nutritivo que pode ser agregado com os ingredientes de seu recheio. Este fato fez com que ela deixasse de ser comercializada apenas em pizzarias, passando a ser oferecida em outros estabelecimentos comerciais, dentre eles o supermercado, que vendem o produto congelado e semi-pronto para o consumo (PINHO et al., 2001).

A produção, consumo e aceitabilidade da pizza vem aumentando significativamente e espera-se que aumente mais na próxima década em resposta a uma população crescente do mundo. Dados Irlandeses mostram que o mercado congelado da pizza aumentou quase $24 \%$ entre 1999 e 2002, sendo que a produção de massa congelada da pizza é importante para manter o mercado. (DELAHAYE et al., 2005; DU; SUN, 2008).

Não existem dados oficiais sobre o consumo de pizza no Brasil. Segundo a Pesquisa de Orçamentos Familiares - POF 2002-2003 (IBGE, 2004), a aquisição per capita de massa de pizza no país foi de $0,168 \mathrm{Kg}$. Dentre as regiões do país, a região Sul teve o maior consumo per capita, 0, $347 \mathrm{Kg}$, seguida da região Centro- Oeste, 0, $202 \mathrm{Kg}$ e da região Sudeste, 0, $185 \mathrm{Kg}$.

Por ser um produto bastante consumido, de baixo custo e que, dependendo do recheio, pode ser um alimento bastante nutritivo (PINHO et al., 2001), o grande interesse por parte dos celíacos em encontrar no mercado pizzas que possam ser consumidas por eles reflete a importância de desenvolver massas isentas de glúten e com boa aceitabilidade pelo público em questão.

As características da pesquisa, metodologia e local do estudo em questão são descritos no capítulo 3 . 


\section{Materiais e Métodos}

\section{1- Delineamento Experimental:}

Foram formulados três tipos de massa para pizza, a partir de farinha de arroz industrializada e de arroz polido. Foi realizada Análise Sensorial e elaborada Ficha Técnica de Preparação para cada formulação obtida.

A receita original para as massas foi obtida em livros de receitas e a partir disso, foram feitas as devidas modificações, substituindo-se a farinha de trigo pela farinha de arroz e modificando-se as quantidades dos outros ingredientes de acordo com a característica de cada tipo de massa utilizada.

A revisão de literatura foi realizada a partir de textos em inglês, português e espanhol de revistas indexadas no Portal de Periódicos da Capes, SciELO, além de livros, dissertações, teses, portais e do buscador Google scholar. Os descritores utilizados durante a pesquisa foram: doença celíaca, glúten, farinha de arroz, arroz, pizza e dieta livre de glúten.

\section{2- Local de Estudo:}

As formulações e as análises sensoriais foram desenvolvidas no Laboratório de Técnica Dietética do Departamento de Nutrição - FS/ UnB. Foram montadas cabines no local para evitar comunicação entre os provadores com descrito por Dutcosky (2007).

\section{3- Ficha Técnica de Preparação:}

As Fichas Técnicas de Preparação foram elaboradas durante a formulação dos produtos, como descrito por Botelho e Camargo (2005) e constam as seguintes informações: quantidade dos ingredientes, tempo total de preparação (pré-preparação e preparação), quantidade per capita, informação nutricional - macro e alguns micronutrientes, rendimento, lista de ingredientes por ordem de uso: peso, medida ou número de ingredientes e característica nutricional do prato. 
Para o cálculo das informações nutricionais utilizou-se a Tabela Brasileira de Composição de Alimentos-TACO (NEPA-UNICAMP, 2006), além da Tabela de Composição de Alimentos- ENDEF (IBGE, 1999).

\section{4- Análise Sensorial:}

O teste utilizado para verificar a aceitação e preferência dos degustadores foi a Escala hedônica não estruturada de $9 \mathrm{~cm}$, com os extremos "Desgostei extremamente" e "Gostei extremamente" (CHAVES; SPROESSER, 2005). Com este teste avaliou-se os atributos sensoriais presentes: aparência, aroma, sabor e impressão global de cada uma das amostras.

A escala hedônica serve para medir o sentimento de gostar ou desgostar de um produto pelos provadores. A escala não estruturada é uma representação gráfica em linha simples, geralmente de 9 ou $15 \mathrm{~cm}$, ancorada com dois extremos que podem indicar o gostar ou não do produto. Nela o provador marca um traço no ponto da escala que represente sua aceitação. Para analisar os dados do teste, deve-se medir com régua a distância marcada pelo provador ao longo da escala a partir do extremo esquerdo (DUTCOSKY, 2007).

A análise sensorial das formulações foi realizada por equipe não treinada, composta por alunos, funcionários e visitantes da Faculdade de Saúde da UnB. Participaram do estudo 42 degustadores, com idade entre 12 e 53 anos, de ambos os sexos. Todos os provadores foram instruídos sobre a forma correta de aplicação do teste e a importância do enxágue bucal entre a degustação de cada amostra.

As amostras foram servidas simultaneamente em pratos descartáveis codificados com três números cada, obtidos em tabela de números aleatórios, gerada a partir da função Aleatórioenter, do Micrososft@ EXCEL 2000. Além das amostras, receberam a ficha de análise (Figura 01) e água em temperatura ambiente.

Foram excluídos da análise indivíduos com alergia ou intolerância a qualquer um dos ingredientes das formulações, além de pessoas com gripe ou com alguma patologia na cavidade bucal. 


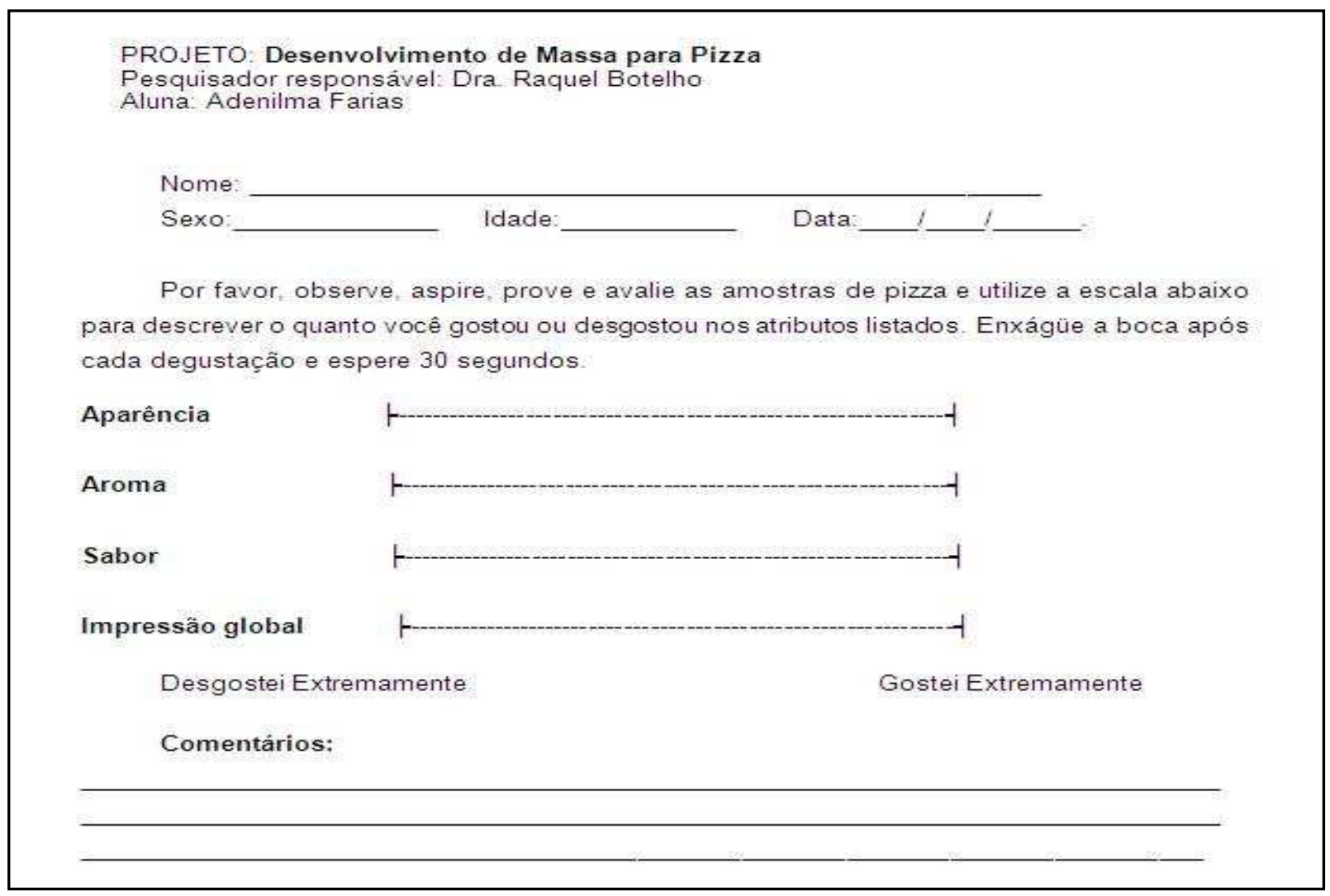

Figura 01. Modelo de ficha de análise sensorial.

FONTE: CHAVES; SPROESSER (2005), adaptado.

\section{5- Aspectos Éticos do Estudo:}

Os julgadores que fizeram parte da avaliação sensorial, antes dos testes, foram informados sobre os objetivos e metodologia da pesquisa e consultados por meio de um Termo de Consentimento, conforme as diretrizes e normas para pesquisa com seres humanos, RESOLUÇÃO 196/96 (BRASIL, 1996).

\section{6- Análise dos Dados:}

As análises de dados foram feitas utilizando-se o Programa Epi-Info, versão 6.04b (CDC/WHO,1996). Os testes utilizados foram Teste de Tukey e ANOVA (DUTCOSKY, 2007). O nível de significância adotado foi de 5\%.

O Capítulo 4 descreve os resultados obtidos no estudo e a discussão do mesmo. 


\section{Resultados e Discussão}

De acordo com a ANVISA (Agência Nacional de Vigilância Sanitária), os alimentos destinados aos celíacos são denominados alimentos para fins especiais, pois são alimentos modificados onde o ingrediente fonte de glúten é substituído por outro que não contenha esta proteína, para que possa atender às necessidades desta população específica (BRASIL, 1998).

Nas três formulações de pizza houve a substituição total da farinha de trigo por farinha de arroz, partindo-se de uma fórmula tradicional adquirida em livro de receita (Apêndice A).

Em todas as preparações, a farinha de arroz foi submetida à cocção antes de se acrescentar os outros ingredientes da massa, com o intuito de obter a gelatinização do amido. A geleificação melhora a adesão da massa, tornando-a mais moldável, enquanto que a farinha não submetida ao calor tem maior dificuldade de absorver água, conseqüentemente menor viscosidade (ARAÚJO et al., 2007). Além disso, foi acrescentado o polvilho doce nas três formulações, a fim de melhorar a elasticidade da massa. Os percentuais de ingredientes utilizados nas preparações padrão e modificadas estão ilustrados na Tabela 01.

Tabela 01. Percentual de ingredientes das preparações de massa para pizza a partir de farinha de arroz refinada, farinha de arroz flocada, arroz polido e farinha de trigo. Brasília-DF, dezembro de 2008.

\begin{tabular}{c|c|c|c|c}
\hline \multirow{2}{*}{ Ingrediente } & \multicolumn{4}{|c}{ Amostras } \\
\cline { 2 - 5 } & $\begin{array}{c}\text { Farinha de } \\
\text { Arroz Refinada }\end{array}$ & $\begin{array}{c}\text { Farinha de } \\
\text { Arroz Flocada }\end{array}$ & Arroz Polido & $\begin{array}{c}\text { Farinha de } \\
\text { Trigo }\end{array}$ \\
\hline Farinha & $53,00 \%$ & $50,30 \%$ & $68,50 \%$ & $41,30 \%$ \\
\hline Leite & $26,50 \%$ & $30,20 \%$ & --- & $31,00 \%$ \\
\hline Ovo & $12,70 \%$ & $12,07 \%$ & $8,22 \%$ & $16,52 \%$ \\
\hline Açúcar & $1,60 \%$ & $1,51 \%$ & $1,03 \%$ & $0,34 \%$ \\
\hline Sal & $0,40 \%$ & $0,38 \%$ & $0,34 \%$ & $0,52 \%$ \\
\hline Fermento & $0,50 \%$ & $0,50 \%$ & $0,51 \%$ & $5,16 \%$ \\
Biológico & & & & \\
\hline Óleo & $1,30 \%$ & $1,26 \%$ & $0,86 \%$ & $5,16 \%$ \\
\hline Polvilho & $4,00 \%$ & $3,77 \%$ & $3,42 \%$ & --- \\
\hline
\end{tabular}


Durante a formulação das massas, foi possível elaborar as Fichas Técnicas de Preparação das mesmas, a fim de padronizar a receita modificada, possibilitando a execução por qualquer outra pessoa que necessite ou se interesse por elas (Apêndices B, C e D).

Akutsu et al. (2005) citam os benefícios da elaboração da Ficha Técnica de Preparação (FTP), dentre eles a possibilidade de se obter dados como tempo de preparo e prépreparo da receita, informação nutricional, rendimento e per capta da preparação. Além disso, pode ser um bom instrumento para o controle da produção, evitando desperdícios, visto que reduz a possibilidade de erro durante a confecção, proporcionando mais segurança.

O tempo de execução das preparações da farinha de arroz refinada e flocada foram semelhantes, já a preparação com arroz polido necessitou de um tempo maior devido ao remolho dos grãos. Tal procedimento foi feito com o intuito de torná-lo mais fácil de ser fracionado para a elaboração da massa. A água do remolho foi utilizada para cocção do mesmo, representando $17,12 \%$ dos ingredientes.

As formulações desenvolvidas, além de rendimentos compatíveis com o da preparação original, tiveram valor acessível. O custo de cada preparação pode ser visualizado na Tabela 02, onde é possível observar que as formulações alternativas, apesar de possuírem um ingrediente a mais, o polvilho, tiveram um custo bem inferior à formulação padrão.

Tabela 02. Amostras de massas para pizza e custo obtido em 100g das preparações. Brasília-DF, dezembro de 2008.

\begin{tabular}{c|c}
\hline Amostra & Custo por 100 g \\
\hline Farinha de Arroz Refinada & $\mathrm{R} \$ 0,43$ \\
\hline Farinha de Arroz Flocada & $\mathrm{R} \$ 0,43$ \\
\hline Arroz Polido & $\mathrm{R} \$ 0,31$ \\
\hline Farinha de Trigo & $\mathrm{R} \$ 1,01$ \\
\hline
\end{tabular}

A principal diferença entre as preparações foi a quantidade de líquido utilizado, que influenciou no Valor Energético Total (VET) e na quantidade de cálcio e ferro. A quantidade de carbiodratos variou principalmente pelo tipo e quantidade de farinha utilizada. A tabela 03 mostra a quantidade de macronutrientes e de micronutrientes (cálcio e ferro), sem recheio, das massas elaboradas a partir das farinhas, do arroz polido e da farinha de trigo. 
Tabela 03. Comparação de macronutrientes e micronutrientes das massas elaboradas a partir de farinha de arroz flocada, farinha de arroz refinada, arroz polido e farinha de trigo sem recheio. Brasília-DF, dezembro de 2008.

\begin{tabular}{c|c|c|c|c}
\hline \multirow{2}{*}{$\begin{array}{c}\text { Nutrientes em } \\
\mathbf{1 0 0 g}\end{array}$} & \multicolumn{4}{|c}{ Amostras } \\
\cline { 2 - 5 } & $\begin{array}{c}\text { Farinha de } \\
\text { Arroz Refinada }\end{array}$ & $\begin{array}{c}\text { Farinha de } \\
\text { Arroz Flocada }\end{array}$ & Arroz Polido & $\begin{array}{c}\text { Farinha de } \\
\text { Trigo }\end{array}$ \\
\hline VET & $284,62 \mathrm{kcal}$ & $249,47 \mathrm{kcal}$ & $113,71 \mathrm{kcal}$ & $291,13 \mathrm{kcal}$ \\
\hline Carboidrato & $58,63 \mathrm{~g}$ & $50,98 \mathrm{~g}$ & $22,05 \mathrm{~g}$ & $40,18 \mathrm{~g}$ \\
\hline Proteína & $3,84 \mathrm{~g}$ & $3,51 \mathrm{~g}$ & $2,71 \mathrm{~g}$ & $9,81 \mathrm{~g}$ \\
\hline Lipídeo & $3,86 \mathrm{~g}$ & $3,50 \mathrm{~g}$ & $1,63 \mathrm{~g}$ & $9,85 \mathrm{~g}$ \\
\hline Ferro & $19,10 \mathrm{mg}$ & $16,54 \mathrm{mg}$ & $0,22 \mathrm{mg}$ & $1,01 \mathrm{mg}$ \\
\hline Cálcio & $44,93 \mathrm{mg}$ & $45,25 \mathrm{mg}$ & $6,87 \mathrm{mg}$ & $64,02 \mathrm{mg}$ \\
\hline
\end{tabular}

A fim de se obter produtos mais saudáveis, a quantidade de óleo das preparações foi intencionalmete reduzida. Esta redução refletiu em menor VET e teor lipídico das preparações.

Ao se compar os valores nutricionais das massas modificadas com a receita original, pode-se observar que a massa elaborada com trigo possui maior VET, maior teor protéico e lipídico. Quanto ao valor de carboidrado, a massa tradicional possiu uma menor quantidade, comparando-se as preparações com farinha de arroz flocada e refinada, e maior quando comparada à formulação com arroz polido. Estes valores podem ser justificados pela composição química das farinhas, pois a farinha de arroz possui maior VET e maior quantidade de carboidrato que a farinha de trigo e o arroz polido (TACO, 2006). Agregado a isso, a utilização do leite nas preparações de farinha de arroz refinada, farinha de arroz flocada e farinha de trigo contribuiu com 4, 27\%; 5, 08\% e 7, 78\% dos VETs respectivamente.

A quantidade de cálcio da formulação padrão é maior, um dos fatores é a maior quantidade de leite utilizada. Quanto ao ferro, apenas a formulação com arroz polido apresentou nível inferior à formulação padrão, a não utilização do leite nessa preparação é a principal responsável por este resultado.

Por ser uma preparação que envolve ingredientes de vários grupos alimentares (cereal, ovo, leite, etc.), a pizza é uma opção válida na alimentação de portadores de DC visto que a maioria dos alimentos sem glúten tem baixa quantidade de micronutrientes. Considerando-se que a proteína do arroz é de baixo valor biológico, os demais ingredientes como o leite e o ovo servem para melhorar a qualidade nutritiva da preparação (ROSEFL; MARCO, 2008). 
O recheio escolhido para as preparações foi o de mussarela, objetivando-se que este influenciasse o mínimo possível no sabor das massas. No entanto, os recheios de pizza servem não somente para conferir sabor mais agradável, mas para melhorar as características nutricionais da mesma. Algumas escolas já incluíram a pizza na merenda escolar (PINHO et al., 2001), visto que a possibilidade de agregar valor nutritivo a esta preparação a partir do recheio, faz com que a pizza possa ser considerada como uma pequena refeição.

De acordo com a ANVISA, o Valor Diário de Referência (VDR) de energia é de 2000 Kcal. Considerando-se que o lanche deve compor 10\% do VET diário, uma porção de pizza pode representar este valor, dependendo do recheio escolhido. Para o portador de DC, a boa seleção do recheio representa tanto a melhoria na composição nutricional da dieta, quanto uma boa forma de inclusão social.

Além de boas características nutricionais, uma preparação modificada necessita ter bom aspecto psicossensorial.

Um alimento modificado desenvolvido para atender a um grupo de indivíduos com restrição a qualquer nutriente pode sofrer alteração em suas características sensoriais. A análise sensorial tem fundamental importância para avaliar aceitação ou rejeição do produto, além das características sensoriais envolvidas (GINANI et al., 2007).

A Análise Sensorial é um instrumento bastante utilizado para avaliar aceitabilidade, comparar e diferenciar atributos sensoriais de um alimento. Com ela é possível utilizar as habilidades humanas para se obter dados estatísticos sobre estes atributos de um alimento ou bebida (FERREIRA, 1999).

A ANOVA revelou que os três produtos foram aceitos pelos participantes (Tabela 04). Com a comparação das médias, pode-se observar que não há diferença estatística entre as amostras, com a probabilidade de $5 \%$ de erro.

Para análise das médias, a nota 5 representa indiferença, enquanto notas abaixo de 5 significam rejeição e notas acima de 5 significam aceitação. As médias das variáveis analisadas das três formulações estão acima de 5, mostrando aceitação da aparência, aroma, sabor e impressão global das três preparações. 
Tabela 04. Médias de aceitação das variáveis analisadas nas três amostras modificadas de pizza. Brasília-DF, dezembro de 2008.

\begin{tabular}{c|c|c|c}
\hline \multirow{2}{*}{ Variáveis } & \multicolumn{3}{|c}{ Amostras } \\
\cline { 2 - 4 } & Refinada & Flocada & Arroz \\
\hline Aparência & $6,64 \pm 0,89^{\mathrm{a}}$ & $6,61 \pm 0,65^{\mathrm{a}}$ & $7,04 \pm 0,45^{\mathrm{a}}$ \\
\hline Aroma & $7,02 \pm 0,72^{\mathrm{a}}$ & $6,23 \pm 0,46^{\mathrm{a}}$ & $6,88 \pm 0,59^{\mathrm{a}}$ \\
\hline Sabor & $7,00 \pm 0,91^{\mathrm{a}}$ & $6,02 \pm 0,72^{\mathrm{a}}$ & $7,19 \pm 0,59^{\mathrm{a}}$ \\
\hline Impressão Global & $6,76 \pm 0,23^{\mathrm{a}}$ & $6,07 \pm 0,49^{\mathrm{a}}$ & $6,95 \pm 0,58^{\mathrm{a}}$ \\
\hline
\end{tabular}

Médias com letras iguais na mesma linha não diferem significativamente entre si, de acordo com o teste de Tukey ao nível de $5 \%$ de probabilidade.

A boa aceitabilidade das três formulações reflete em mais opções para os celíacos, visto que a não disponibilidade de uma das farinhas (refinada ou flocada), há a possibilidade de se utilizar o arroz polido com obtenção de uma preparação bem aceita.

Não é fácil para um paciente conformar-se com uma dieta sem glúten, pois pode condicioná-lo ao isolamento social e à deficiência em micronutrientes como vitaminas do complexo B, cálcio, em vitamina $\mathrm{D}$, ferro, zinco, e magnésio além da fibra. Para isso, uma boa orientação de médicos e nutricionistas aos pacientes e seus familiares é de fundamental importância (ARENDT et al., 2008).

A possibilidade de se avaliar sensorialmente os produtos com não celíacos é importante para os avanços nos estudos de produtos alternativos, pois muitos portadores de DC acabam transgredindo a dieta por falta de produtos ofertados ou dificuldade de seus familiares em preparar e aceitar alimentos alternativos. Produzir alimentos com boas características psicosensoriais, além de contribuir com a terapia destes pacientes, auxilia em seu convívio social. 


\section{Conclusão}

Com a análise sensorial do presente estudo, pôde-se verificar a boa aceitabilidade de massa para pizza a base de farinha de arroz. Tal resultado demonstra a viabilidade de se utilizar o arroz e suas farinhas em preparações para portadores de doença celíaca com boa aceitação tanto para o grupo em questão quanto pelos seus familiares e amigos, além do bom rendimento e preço acessível.

Em algumas localidades há dificuldade de se encontrar a farinha de arroz industrializada, no entanto, o trabalho também demonstrou a possibilidade de obtê-la de forma artesanal a partir do arroz branco polido conseguindo-se resultados de aceitação semelhante aos das farinhas industrializadas.

Intencionalmente, optou-se por diminuir a quantidade de óleo utilizada nas preparações, a fim de se obter produtos mais saudáveis. Tal alteração obteve resultados positivos, pois em relação à massa tradicional, as preparações a base de arroz apresentaram melhor perfil energético e lipídico.

Considerando-se que o arroz é bem aceito na culinária mundial, principalmente na brasileira, a elaboração de produtos alimentícios utilizando este cereal e seus derivados torna-se relevante tanto na alimentação convencional quanto na alimentação com restrições, devido a sua propriedade hipoalergênica.

Aliado a isto, há ainda o fato de existirem poucos estudos com elaboração de pizza utilizando-se farinhas alternativas, além da baixa disponibilidade desta preparação no mercado de alimentos sem glúten.

O crescente aumento de diagnósticos de portadores de DC é um dos indicadores da necessidade de se estudar mais alternativas alimentares para este grupo. Tais alimentos devem não somente atender ao requisito de serem isentos de glúten, mas também devem ser acessíveis financeiramente, facilmente executáveis no ambiente familiar e possuírem bom aspecto sensorial. O presente estudo indica que as três preparações modificadas atendem a estes requisitos, podendo então ser introduzidas na dieta de portadores de DC. 


\section{REFERÊNCIAS}

ACELBRA. Associação dos Celíacos do Brasil. Disponível em: http://www.acelbra.org.br. Acessado em: 15 Nov. 2006.

AKUTSU, R. de C.; BOTElho, R. A.; CAMARGO, E. B.; SAVIO, K.; ARAÚJO, W.M. A ficha técnica de preparação como instrumento de qualidade na produção de refeições. Revista de Nutrição, vol.18, no.2, p.277-279, Mar./Abr. 2005.

ALENCAR, M. L. Estudo da prevalência da doença celíaca em doadores de sangue na cidade de São Paulo. 2007. Tese (Doutorado em Ciências)- Faculdade de Medicina da Universidade de São Paulo, São Paulo, 2007.

ARAÚJO, H. M. C.; RAMOS, K. L.; BOTELHO, R. B. A.; ZANDONADI, R. P. Transformação dos Alimentos: Cereais e Leguminosas. In: ARAÚJO, W.M.C.; BOTELHO, R.B.A.; PILLA, N. M. de; BORGO, L. A. Alquimia dos Alimentos. Brasília. Ed. SENAC, 2007.

ARENDT, E. K., MORRISSEY; A.W, MOORE, M. M.; DAL BELLO, F. Gluten-free breads. In: ARENDT, E.; DAL BELlO, F. Gluten-Free Cereal Products and Beverages. Included in series Food Science \& Technology. Hardbound: Elservier, 2008. 464 p. ISBN: 978-0-12373739-7.

BARATA, T.S.B. Caracterização do consumo de arroz no Brasil. In: CONGRESSO BRASILEIRO DE ECONOMIA E SOCIOLOGIA RURAL, 43, 2005, Ribeirão Preto. Anais... Disponível em: http://www.sober.org.br/palestra/2/841.pdf. Fevereiro 2005. Acesso em: 10 Ago. 2008.

BARBOSA, L. DAS N.; GARCIA, L. DE V.; TOLOTTI, K. D.; GOELLNER, T.; AUGUSTORUIZ, W.; SANTO M. E. Elaboração de embutido tipo mortadela com farinha de arroz. Vetor, Rio Grande, v. 13, p. 11-20, 2006. 
Botelho, R. B. A.; CAMARGo, E. B. Técnica Dietética. Seleção e Preparo de Alimentos. Manual de Laboratório. São Paulo: Atheneu, 2005.

BRASIL, MINISTÉRIO DA SAÚDE. Portaria n ${ }^{\circ}$ 29, de 13 de janeiro de 1998. Secretaria de Vigilância Sanitária, do Ministério da Saúde, Regulamento Técnico de Alimentos para Fins Especiais, 1998.

BRASIL, MINISTÉRIO DA SAÚDE. Resolução - RDC n 360, de 23 de dezembro de 2003. Secretaria de Vigilância Sanitária, do Ministério da Saúde, Regulamento Técnico Sobre Rotulagem Nutricional de Alimentos Embalados, 2003.

BRASIL. Ministério da Saúde. Conselho Nacional de Saúde. Resolução n.196/96. Diretrizes e Normas Regulamentadoras de Pesquisas Envolvendo Seres Humanos. Diário Oficial da União, Brasília-DF, 16 out. 1996. Seção 1, p.21.082.

BRUM, L. A., PORTELA, E.F.M. As estratégias da competitividade para a cadeia produtiva do arroz: O caso das Cooperativas da Fronteira-Oeste do Rio Grande do Sul (Brasil). Desenvolvimento em Questão, v.5, n. 9, p 121-146, Jan./Jun. 2007.

CASTRO, E.M.; VIEIRA, N.R.A.; RABELO, R.R.; SILVA, S.A. Qualidade de grãos em arroz. Santo Antônio de Goiás: Embrapa Arroz e Feijão, 1999. 30 p. Disponível em: http://www.cnpaf.embrapa.br/publicacao/circulartecnica/circ_34.pdf. Acesso em: 15 Mai. 2008.

CDC/WHO - Centers for Disease Control/World Health Organization, Epi-Info, versão 6.04b, 1996.

CHAVES, J. B. P.; SPROESSER, R. L. Práticas de laboratório de análise sensorial de alimentos e bebidas. Viçosa: UFV, 2005. 
DELAHAYE, E. P. DE; JIMÉNEZ, P.; PÉREZ, E. Efect of enrichment with high content dietary fiber stabilized rice bran flour on chemical and functional properties of storage frozen pizzas. Journal of Food Engineering, v. 68, p. 1-7, 2005.

DORS, G. C.; CASTIGLIONI, G. L.; AUGUSTO-RUIZ, W. Utilização da farinha de arroz na elaboração de sobremesa. Vetor, Rio Grande, v. 16, p. 63-67, 2006.

DU, C-J; SUN, D-W. Quality Evaluation of Pizzas. Food Quality Evaluation, v. 18, p. 427-446, 2008.

DUTCOSKY, S.D. Análise Sensorial de Alimentos. Curitiba: Champagnat, 2007.

EMBRAPA. Cultivo do Arroz Irrigado no Brasil. Consumo, Mercado e Comercialização do Arroz no Brasil. Disponível em: http:// sistemasdeproducao. cnptia.embrapa.br/ FontesHTML/ Arroz/ ArrozIrrigadoBrasil/ cap18.htm. Acesso em: 15 Mai. 2008.

ESASHIRA, et. AL. O Celíaco e a Dieta - Problemas de Adaptação e Alimentos Alternativos. São Paulo. Pediatria, v. 8, p. 41-44, 1986.

FERREIRA, P.V. Estatística experimental aplicada a Agronomia. 3.ed. Maceió: EDUFAL, 2000. 422 p.

GALERA, J.S. Substituição parcial da farinha de trigo por farinha de arroz (Oryza sativa L.) na produção de "sonho" - estudo modelo. 2006. Dissertação (Mestrado em Ciência de Alimentos) - Faculdade de Ciências Farmacêuticas da Universidade de São Paulo, São Paulo, 2006.

GALVÃO, L. C.; BRANDÃO, J. M. M.; FERNANDES, M. I. M.; CAMPOS, A. D. Apresentação Clínica de Doença Celíaca em Crianças Durante dois Períodos, em Serviço Universitário Especializado. Arquivos de Gastroenterologia, v. 41, n. 4, p. 234-238. Out./Dez. 2004. 
GALLAGHER, E. Formulation and nutritional aspects of gluten-free diet cereal products and infant foods. In: ARENDT, E.; DAL BELLO, F. Gluten-Free Cereal Products and Beverages. Included in series Food Science \& Technology. Hardbound: Elservier, 2008. 464 p. ISBN: 9780-12-373739-7.

GANDOLFI, L.; PRATESI, R.; CORDOBA, J. C.; TAUIL, P. L.; GASPARIN, M.; CATASSI, C. Prevalence of celiac disease among blood donors in Brazil. The American Journal of Gastroenterology. Vol. 95, No. 3, 2000.

GINANI, V. C.; PINELI, L. de L. de O. A estética do gosto. In: ARAÚJO, W.M.C.; BOTELHO, R.B.A.; PILLA, N. M. de; BORGO, L. A. Alquimia dos Alimentos. Brasília. Ed. SENAC, 2007.

GUERREIRO, L. Farinhas não tradicionais. Dossiê Técnico. Serviço Brasileiro de Respostas Técnicas - SBRT. Novembro, 2006. Disponível em: http:// www.respostatecnica.org.br/ dossie.do $\mathbf{a c a o}=$ visualizarDTParcial\&id =23 . Acesso em: 10 ago. 2008.

INSTITUTO BRASILEIRO DE GEOGRAFIA E ESTATÍSTICA (IBGE). Estudo Nacional de Despesa Familiar: Tabela de Composição de Alimentos. Rio de Janeiro: IBGE, 5 ed. 1999.

INSTITUTO BRASILEIRO DE GEOGRAFIA E ESTATÍSTICA (IBGE). Pesquisa de orçamentos familiares, 2002-2003. Rio de Janeiro; 2004.

INSTITUTO BRASILEIRO DE GEOGRAFIA E ESTATÍSTICA (IBGE). Em 2009, safra deve atingir milhões de toneladas. Disponível em: http://www.ibge.gov.br/home/presidencia/noticias/noticia_visualiza.php?id_noticia=1298\&i d_pagina=1

KENNEDY, G.; BURLINGAME, B. Analysis of food composition data on rice from a plant genetic resources perspective. Food Chemistry, v.80, n.4, p. 589-596, 2003. 
KOTZE, L. M. S.. Doença Celíaca: Passado, presente e Futuro. In: Federação Brasileira de Gastroenterologia. (Org.). A Gastroenterologia no Brasil. Subsídios para sua História até o ano 2000. Rio de Janeiro: Revinter, v. 1, p. 241-259, 2001.

KOTZE, L. M. da S. Comparação dos Anticorpos Anti-Reticulina e Antiendomísio Classe Iga Para Diagnóstico e Controle da Dieta na Doença Celíaca. Jornal Brasileiro de Gastroenterologia, Rio de Janeiro, v.6, n.1, p.23-34, jan./mar. 2006

LEE, A.R.; Ng, D.L.; ZIVIN, J.; GREEN, P.H. Economic burden of a gluten-free diet. Journal Human of Nutrition and Dietetic. v. 20, p. 423-430, 2007.

LOPEZ, A.C. B.; PEREIRA, A. J. G.; JUNQUEIRA, R. G. Flour mixture of rice flour, corn and cassava starch in the production of gluten-free white bread. Brazilian Archives of Bioliology and Technology, v. 47, n. 1, p. 63-70, 2004.

MAIA, L. H.; WANG, S. H.; FERNANDES, M. S.; CABRAL. L. C. Características químicas dos mingaus desidratados de arroz e soja. Ciência e Tecnologia de Alimentos, Campinas-SP, v. 20, n..3, Set./Dez. 2000.

MORETTO, E.; FETT, R.; GONZAGA, L.V.; KUSKOSKI, E.M. Introdução à Ciência de Alimentos. Florianópolis : UFSC, 2002. 255p.

NAVES, M.M.V. Características químicas e nutricionais do arroz. Boletim do CEPPA, Curitiba, v. 25, n. 1, jan./jun. 2007.

NEPA-UNICAMP. Tabela brasileira de composição de alimentos. Versão II. 2. ed. Campinas, SP: NEPA-UNICAMP, 2006. 113p.

NEVES, I.P. Cultivo de Arroz. Dossiê Técnico. Serviço Brasileiro de Respostas Técnicas SBRT. Novembro, $2007 . \quad$ Disponível em: www.respostatecnica.org.br/dossie.do?acao=visualizarDTParcial\&id=256 - 21k. Acesso em: 10 Ago. 2008. 
NIEWINSKI, M. M. Advances in Celiac Disease and Gluten-Free Diet. Journal American of Dietetic Association. 108 p. 661-67, 2008.

ORMENESE, R. C. S. C.,et al. Massas Alimentícias Não-convencionais à Base de Arroz . Perfil Sensorial e Aceitação pelo Consumidor. Brazilian Journal of Food and Technology, v. 4, p. 67-74, 2001.

ORMENESE, R. DE C. S. C.; CHANG, Y. K. Massas alimentícias de arroz: uma revisão. Boletim do CEPPA, Curitiba, v. 20, n. 2, jul./dez. 2002.

ORNELLAS, L H - Técnica Dietética: seleção e preparo de alimentos. São Paulo: Ateneu, 2001. 245p.

PEREIRA, M. A. G.; ORTIZ-AGOSTINHO, C. L.; NISHITOKUKADO, I.; SATO, M. N.; DAMIÃO, A. O. M. C.; ALENCAR, M.L.; ABRANTES-LEMOS, C. P.; CANÇADO, E. L. R.; DE BRITO, T.; IOSHII, S. O.; VALARINI, S. B. M.; SIPAHI, A. M. Prevalence of celiac disease in an urban area of Brazil with predominantly European ancestry. World Journal of Gastroenterology. Vol. 12, no 40, p. 6546-6550, 2006.

PHILIPPI, S. T. Nutrição e Técnica Dietética. Barueri: Manole, 2003, p. 51-52.

PINHO, B.H. DA S.; MACHADO, M. I. F.; FURLONG, E. B. Propriedades fİsico-quİmicas das massas de pizza semiprontas e sua relação com o desenvolvimento de bolores e leveduras. Revista do Instituto Adolfo Lutz, vol. 60, n.1, p. 35-41, 2001

PRATESI R, GANDOLFI L. Doença celíaca: a afecção com múltiplas faces. Jornal de Pediatria. Rio de Janeiro, v.81, p. 357-8, 2005.

ROSEFL, C. M.; MARCO, C.. Rice. In: ARENDT, E.; DAL BELLO, F. Gluten-Free Cereal Products and Beverages. Included in series Food Science \& Technology. Hardbound: Elservier, 2008. 464 p. ISBN: 978-0-12-373739-7. 
SDEPANIAN VL, MORAIS MB, FAGUNDES-NETO U. Doença celíaca: a evolução dos conhecimentos desde sua centenária descrição original até os dias atuais. Arquivos de Gastroenterologia, v. 36, p. 244-57, 1999.

SDEPANIAN, V. L.; MORAIS, M. B.; FAGUNTES-NETO, U. DOENÇA CELÍACA: Avaliação da obediência à dieta e do conhecimento da doença pelos pacientes cadastrados na Associação dos Celíacos do Brasil ACELBRA. Arquivos de Gastroenterologia, v. 38, n. 4, p.232:239, out./dez. 2001. a

SDEPANIAN, V. L.; SCALETSKY, I. C. A; MORAIS, M. B. de; FAGUNDES-NETO, U. Pesquisa de gliadina em medicamentos - informação relevante para a orientação de pacientes com doença celíaca. Arquivos de Gastroenterologia, v. 38, n. 3, jul./set. 2001. b

SIMBALISTA, R. L.; ARÊAS, JOSÉ A.G. Desenvolvimento de Pão de Fôrma com Farinha de Linhaça para Avaliar os Possíveis Efeitos nos Sintomas Climatéricos de Mulheres na PósMenopausa. In: Simpósio Brasileiro Sobre Desenvolvimento de Novos Produtos Alimentícios: Alimentos Funcionais e para Fins Especiais. Anais... Campinas: ITAL, maio de 2006. CD-ROM.

THOMPSON T. Do oats belong in a gluten free diet? Journal American of Dietic Association. v. 97, p. 1413-1416, 1997.

VIEIRA, C.R. Extração, hidrólise e remoção de fenilalanina das proteínas de farinha de arroz. 2007. Dissertação (Mestrado em Ciência de Alimentos) - Faculdade de Farmácia da Universidade Federal de Minas Gerais, Minas Gerais, 2007.

WGO - World Gastroenterology Organisation. World Gastroenterology Organisation Practice Guidelines: Celiac Disease. WGO-OMGE, 2005. Disponível em: http://www.omge.org. Acesso em: 10 Jan. 2009. 
ZANDONADI, R. P. Psyllium como substituto de glúten. 2006. Dissertação (Mestrado em Nutrição Humana) - Faculdade de Ciências da Saúde da Universidade de Brasília, Brasília, 2006. 


\section{APÊNDICES}

APÊNDICE A: FICHA TÉCNICA DE PREPARAÇÃO DE MASSA PARA PIZZA COM FARINHA DE TRIGO.

\begin{tabular}{|c|c|c|c|c|c|}
\hline INGREDIENTES & $\begin{array}{c}\text { Peso } \\
\text { Bruto } \\
(\mathrm{g})\end{array}$ & $\begin{array}{c}\text { Peso } \\
\text { líquido } \\
\text { (g) }\end{array}$ & FC & $\begin{array}{c}\text { Per } \\
\text { capita } \\
(\mathrm{g}) \\
\end{array}$ & Modo de Preparo \\
\hline Farinha de trigo & 240,00 & 240,00 & 1,00 & 20,00 & \multirow{7}{*}{$\begin{array}{l}\text { - Aquecer o leite, dissolver o fermento nele e juntar o } \\
\text { óleo, o sal e o açúcar; } \\
\text {-Peneirar a farinha de trigo numa vasilha e abrir um } \\
\text { buraco no centro; } \\
\text {-Adicionar a mistura de leite e óleo e sovar com as mãos } \\
\text { por uns } 15 \text { minutos até que a massa comece a soltar da } \\
\text { mão; } \\
\text {-Abrir a massa com um rolo e colocar em fôrma untada; } \\
\text {-Levar ao forno pré-aquecido a } 180^{\circ} \mathrm{C} \text { por cerca de } 20 \\
\text { minutos. }\end{array}$} \\
\hline Leite integral & 180,00 & 180,00 & 1,00 & 15,00 & \\
\hline Ovo & 100,00 & 96,00 & 1,04 & 8,00 & \\
\hline Açúcar & 2,00 & 2,00 & 1,00 & 0,17 & \\
\hline Sal & 3,00 & 3,00 & 1,00 & 0,25 & \\
\hline Fermento biológico & 30,00 & 30,00 & 1,00 & 2,50 & \\
\hline Óleo vegetal & 30,00 & 30,00 & 1,00 & 2,50 & \\
\hline
\end{tabular}

Valor Energético Total - VET: 1411, $98 \mathrm{Kcal}$

VET por Porção: 117, $67 \mathrm{Kcal}$

Carboidratos: $194,90 \mathrm{~g}$ $779,60 \mathrm{Kcal}$ $(55,70 \%$ do VET $)$

Proteínas: 47,58g 190,32 Kcal $(13,60 \%$ do VET $)$

Lipídeos: 47, 75 $429,75 \mathrm{Kcal}$ $(30,70 \%$ do VET $)$

Ferro: $4,9 \mathrm{mg}$

Cálcio: $310,48 \mathrm{mg}$

Fator de cocção/Fator de conversão: 0,78

Rendimento (massa): $485 \mathrm{~g}$

Porção (massa): 40,42g

Rendimento (medida caseira-massa): 12 fatias médias

Tempo total da preparação: 45 Minutos 
APÊNDICE B: FICHA TÉCNICA DE PREPARAÇÃO DE PIZZA COM FARINHA DE ARROZ FLOCADA.

\begin{tabular}{|c|c|c|c|c|c|}
\hline INGREDIENTES & $\begin{array}{c}\text { Peso } \\
\text { Bruto } \\
\text { (g) }\end{array}$ & $\begin{array}{c}\text { Peso } \\
\text { líquido } \\
\text { (g) }\end{array}$ & FC & $\begin{array}{c}\text { Per } \\
\text { capita } \\
(\mathrm{g})\end{array}$ & Modo de Preparo \\
\hline $\begin{array}{c}\text { Farinha de arroz } \\
\text { flocada }\end{array}$ & 200,00 & 200,00 & 1,00 & 16,70 & \multirow{10}{*}{$\begin{array}{l}\text {-Juntar a farinha de arroz e o leite em uma panela e levar } \\
\text { ao fogo, mexendo bem por } 3 \text { minutos. } \\
\text {-Colocar a mistura ainda quente em uma bacia e } \\
\text { acrescentar o sal, o açúcar, o fermento biológico, o ovo, } \\
\text { o óleo, deixando o polvilho por último. } \\
\text { - Sovar a massa, colocar em um recipiente menor e } \\
\text { cobrir com tampa ou papel filme e em seguida deixar } \\
\text { descansar por } 30 \text { minutos (até a massa crescer). } \\
\text {-Forrar a mesa com um saco plástico limpo (aberto) e } \\
\text { colocar a massa, cobrir em seguida com outro saco para } \\
\text { que possa abrir com um rolo apropriado. } \\
\text {-Untar uma fôrma com óleo e colocar a massa, levar em } \\
\text { seguida ao forno pré-aquecido em temperatura de } 180^{\circ} \\
\text { por } 12 \text { minutos. } \\
\text { - Retirar a massa do forno e acrescentar o molho de } \\
\text { tomate e o recheio de mussarela, em seguida levar ao } \\
\text { forno novamente por } 10 \text { minutos. }\end{array}$} \\
\hline Leite integral & 120,00 & 120,00 & 1,00 & 10,00 & \\
\hline Ovo & 50,00 & 48,00 & 1,04 & 4,00 & \\
\hline Açúcar & 6,00 & 6,00 & 1,00 & 0,50 & \\
\hline Sal & 1,50 & 1,50 & 1,00 & 0,13 & \\
\hline Fermento biológico & 2,00 & 2,00 & 1,00 & 0,17 & \\
\hline Óleo vegetal & 5,00 & 5,00 & 1,00 & 0,42 & \\
\hline Polvilho doce & 15,00 & 15,00 & 1,00 & 1,25 & \\
\hline Molho de tomate & 65 & 65 & 1,00 & 5,42 & \\
\hline Queijo Mussarela & 160 & 160 & 1,00 & 13,33 & \\
\hline
\end{tabular}

VET TOTAL: $1441,45 \mathrm{Kcal}$

VET por Porção: 120, $12 \mathrm{Kcal}$

Carboidratos: $205,36 \mathrm{~g}$ $821,44 \mathrm{Kcal}$ $(56,99 \%$ do VET)

Proteínas: $45,54 \mathrm{~g}$ $182,16 \mathrm{Kcal}$ $(12,64 \%$ do VET)

Lipídeos: 48, 65g $437,85 \mathrm{Kcal}$ $(30,38 \%$ do VET $)$

Ferro: $65,16 \mathrm{mg}$

Cálcio: 1009, 65 mg

Fator de cocção/Fator de conversão: 0,98

Rendimento (massa): $386 \mathrm{~g}$

Porção (massa): $32,17 \mathrm{~g}$

Rendimento - massa (medida caseira): 12 fatias médias

Tempo total da preparação: 57 minutos 
APÊNDICE C: FICHA TÉCNICA DE PREPARAÇÃO DE PIZZA COM ARROZ POLIDO.

\begin{tabular}{|c|c|c|c|c|c|}
\hline INGREDIENTES & $\begin{array}{c}\text { Peso } \\
\text { Bruto } \\
(\mathrm{g})\end{array}$ & $\begin{array}{c}\text { Peso } \\
\text { líquido } \\
\text { (g) }\end{array}$ & FC & $\begin{array}{c}\text { Per } \\
\text { capita } \\
(\mathrm{g}) \\
\end{array}$ & Modo de Preparo \\
\hline Arroz Polido & 400,00 & 400,00 & 1,00 & 25,00 & \multirow{10}{*}{$\begin{array}{l}\text {-Deixar o arroz de molho na água por no mínimo } 3 \text { horas. } \\
\text {-Bater o arroz com a água no liquidificador em velocidade } \\
\text { média até triturar bem. } \\
\text {-Colocar a mistura em uma panela e levar ao fogo, mexendo } \\
\text { sempre para não embolar, até que a água seque totalmente e } \\
\text { se obtenha uma massa firme. } \\
\text {-Transferir a mistura ainda quente em uma bacia e } \\
\text { acrescentar o sal, o açúcar, o fermento biológico, o ovo, o } \\
\text { óleo, deixando o polvilho por último. } \\
\text { - Sovar a massa, colocar em um recipiente menor e cobrir } \\
\text { com tampa ou papel filme e em seguida deixar descansar } \\
\text { por } 30 \text { minutos (até a massa crescer). } \\
\text {-Forrar a mesa com um saco plástico limpo (aberto) e } \\
\text { colocar a massa, cobrir em seguida com outro saco para que } \\
\text { possa abrir com um rolo apropriado. } \\
\text {-Untar uma fôrma com óleo e colocar a massa, levar em } \\
\text { seguida ao forno pré-aquecido em temperatura de } 180^{\circ} \text { por } \\
08 \text { minutos. } \\
\text { - Retirar a massa do forno e acrescentar o molho de tomate e } \\
\text { o recheio de mussarela, em seguida levar ao forno } \\
\text { novamente por } 10 \text { minutos. }\end{array}$} \\
\hline Água & 100,00 & 100,00 & 1,00 & 6,25 & \\
\hline Ovo & 50,00 & 48,00 & 1,04 & 3,00 & \\
\hline Açúcar & 6,00 & 6,00 & 1,00 & 0,38 & \\
\hline Sal & 2,00 & 2,00 & 1,00 & 0,13 & \\
\hline $\begin{array}{l}\text { Fermento } \\
\text { biológico }\end{array}$ & 3,00 & 3,00 & 1,00 & 0,19 & \\
\hline Óleo vegetal & 5,00 & 5,00 & 1,00 & 0,31 & \\
\hline Polvilho doce & 20,00 & 20,00 & 1,00 & 1,25 & \\
\hline Molho de tomate & 65 & 65 & 1,00 & 4,06 & \\
\hline Queijo Mussarela & 160 & 160 & 1,00 & 10,00 & \\
\hline
\end{tabular}

VET TOTAL: $1183,74 \mathrm{Kcal}$

VET por Porção: 73,98 Kcal

Carboidratos: $145,29 \mathrm{~g}$

Proteínas: $48,81 \mathrm{~g}$

Lipídeos: 45, $26 \mathrm{~g}$

Ferro: $2,9 \mathrm{mg}$

Cálcio: $877,58 \mathrm{mg}$

Fator de cocção/Fator de conversão: 0,63

Rendimento (massa): $620 \mathrm{~g}$

Porção (massa): $38,75 \mathrm{~g}$

Rendimento - massa (medida caseira): 16 fatias médias

Tempo total da preparação: 60 minutos (sem o tempo de remolho do arroz) 
APÊNDICE D: FICHA TÉCNICA DE PREPARAÇÃO DE PIZZA COM FARINHA DE ARROZ REFINADA.

\begin{tabular}{|c|c|c|c|c|c|}
\hline INGREDIENTES & $\begin{array}{c}\text { Peso } \\
\text { Bruto } \\
(\mathrm{g})\end{array}$ & $\begin{array}{c}\text { Peso } \\
\text { líquido } \\
\text { (g) }\end{array}$ & FC & $\begin{array}{c}\text { Per } \\
\text { capita } \\
(\mathrm{g})\end{array}$ & Modo de Preparo \\
\hline $\begin{array}{c}\text { Farinha de arroz } \\
\text { refinada }\end{array}$ & 200,00 & 200,00 & 1,00 & 16,70 & \multirow{10}{*}{$\begin{array}{l}\text {-Juntar a farinha de arroz e o leite em uma panela e levar } \\
\text { ao fogo, mexendo bem por } 3 \text { minutos. } \\
\text {-Colocar a mistura ainda quente em uma bacia e } \\
\text { acrescentar o sal, o açúcar, o fermento biológico, o ovo, o } \\
\text { óleo, deixando o polvilho por último. } \\
\text { - Sovar a massa, colocar em um recipiente menor e cobrir } \\
\text { com tampa ou papel filme e em seguida deixar descansar } \\
\text { por } 30 \text { minutos (até a massa crescer). } \\
\text {-Forrar a mesa com um saco plástico limpo (aberto) e } \\
\text { colocar a massa, cobrir em seguida com outro saco para } \\
\text { que possa abrir com um rolo apropriado. } \\
\text {-Untar uma fôrma com óleo e colocar a massa, levar em } \\
\text { seguida ao forno pré-aquecido em temperatura de } 180 \text { o } \\
\text { por } 12 \text { minutos. } \\
\text { - Retirar a massa do forno e acrescentar o molho de tomate } \\
\text { e o recheio de mussarela, em seguida levar ao forno } \\
\text { novamente por } 10 \text { minutos. }\end{array}$} \\
\hline Leite integral & 100,00 & 100,00 & 1,00 & 8,33 & \\
\hline Ovo & 50,00 & 48,00 & 1,04 & 4,00 & \\
\hline Açúcar & 6,00 & 6,00 & 1,00 & 0,50 & \\
\hline Sal & 1,50 & 1,50 & 1,00 & 0,13 & \\
\hline $\begin{array}{l}\text { Fermento } \\
\text { biológico }\end{array}$ & 2,00 & 2,00 & 1,00 & 0,17 & \\
\hline Óleo vegetal & 5,00 & 5,00 & 1,00 & 0,42 & \\
\hline Polvilho doce & 15,00 & 15,00 & 1,00 & 1,25 & \\
\hline Molho de tomate & 65 & 65 & 1,00 & 5,42 & \\
\hline Queijo Mussarela & 160 & 160 & 1,00 & 13,33 & \\
\hline
\end{tabular}

VET TOTAL: $1429,25 \mathrm{Kcal}$

VET por Porção: 119,10 Kcal

Carboidratos: 204, 38g

817,52 Kcal

(57, 2\% do VET)

Proteínas: 44,82g

$179,28 \mathrm{Kcal}$

$(12,54 \%$ do VET)

Lipídeos: 48, 05g

432,45 Kcal

$(30,26 \%$ do VET $)$

Ferro: 65, $14 \mathrm{mg}$

Cálcio: 985, $05 \mathrm{mg}$

Fator de cocção/Fator de conversão: 0,92

Rendimento (massa): $334 \mathrm{~g}$

Porção (massa): 27,83g

Rendimento - massa (medida caseira): 12 fatias médias

Tempo total da preparação: 57 minutos 